\title{
The Student Conference: A Model of Authentic Assessment
}

\author{
http://dx.doi.org/10.3991/ijep.v4i2.3445 \\ T. L. Larkin \\ American University, Washington, DC USA
}

\begin{abstract}
In the global marketplace, the ability to communicate, both orally and in writing, is a skillset demanded by employers. Unfortunately, typical academic exercises that involve written and oral communication are often just that ... academic exercises. To provide a more authentic and robust experience, a student conference activity has been developed for use in a second-level physics course entitled Physics for a New Millennium (PNM) at American University (AU). This activity involves writing a formal research paper using professional guidelines. In addition, students present their research paper during a class event modeled after an actual professional conference. A focus of this paper is to discuss the assessment strategies developed for the conference paper activity. A major goal of the assessment strategies designed for the conference paper and the associated presentation is to better capture (and then assess) what students are actually learning in the course. This paper will provide an overview of the student conference paper activity with emphasis on its value as an alternative assessment tool. To that end, a synopsis of how the conference paper activity has been designed will be shared. This synopsis will begin with a general discussion of assessment, assessment methods, and the "language of assessment." Following this synopsis a model of non-traditional assessment using the student conference paper will be highlighted. Subsequently a description of the course curriculum and the specific structure for the writing activity will be outlined as they relate to the learning outcomes for the course. Shadowing the presentation of the course-specific learning outcomes, a description of the strategies used to uncover student learning will be shared. These strategies provide an opportunity for multiple assessment "snapshots" to be made throughout various phases of the learning process. To illustrate these snapshots, examples from actual student work will be presented and discussed. The assessment strategies developed for the student conference paper can be used as an alternative, or as a supplement, to more traditional pencil and paper examinations, quizzes, and homework assignments. Whether used as a stand-alone assessment tool or coupled with more traditional measures, the model presented here can provide an enhanced and more authentic way to capture what students are actually learning while the learning is taking place.
\end{abstract}

Index Terms-Alternative assessment, assessment models, authentic assessment, formative assessment, learning goals and objectives, learning outcomes, student writing, written and oral communication.

\section{INTRODUCTION}

How can we really assess what students are learning? What can we learn from traditional assessment measures? Do traditional assessment measures really provide us with a robust picture of what students are learning throughout all facets of the learning process? Questions such as these provide the motivation for this paper.

Studies on teaching pedagogies have clearly demonstrated that traditional techniques often put students in a role of passive rather than active learning [1 - 5]. Furthermore, more traditional methods have been shown to be very inadequate in terms of promoting deep learning and long-term retention of important concepts [6 - 9]. Students in traditional classrooms often acquire most of their knowledge through passive classroom lectures, textbook reading, and the internet. Passive learning routinely results in students merely trying to learn and regurgitate what the teacher and textbook are telling them. A discouraging fact is, after instruction, students often emerge from our classes with serious misconceptions $[10-16]$. Writing can be used to effectively help students confront their misconceptions. In addition, formal writing strategies can provide essential "snapshots" to help uncover what students are really learning as the learning is taking place.

Traditional examinations and quizzes merely provide an assessment marker after a segment of material has been covered in class. While important as a point for charting progress, these forms of assessment do little to uncover what is actually taking place in the mind of the learner. Astin [17] argues that as professors, we may think that we've given a very stimulating and thought-provoking lecture, without ever really knowing how much of it was actually understood by the students, how much was retained, or whatever other kinds of effects it may have had on the students. While traditional examinations and quizzes may provide us with some information about what students are learning, this more summative type of feedback really comes a little too late. A carefully crafted writing activity or set of activities can provide a more formative and authentic assessment of student learning; and, give students and professors time to correct any misconceptions or flaws in reasoning as the learning is ongoing. The particular writing-based assessment activity to be showcased in this paper was developed for use in a second-level physics course for non-majors. Before discussing the writing activity, some details about the course setting will be presented.

\section{Course Structure AND Setting}

A second-level physics course for non-majors entitled Physics for a New Millennium (PNM) at American University (AU) serves as the setting for this project. Designed by the author, this course is taught in an interactive studio/workshop format. Numerous projects and studies within the domain of Physics Education Research (PER) have pointed to the importance and value of using a learner-centered, activity-based environment. A significant 
outcome of these and other PER studies is; in comparison to more traditional instructional strategies, student conceptual understanding and problem-solving ability is enhanced within an activity-based learning environment [18 $-25]$.

PNM is a course that many students take to satisfy the university's General Education requirements towards graduation. A unique element of the PNM course is its active learning format along with its focus on student writing as an alternative method of assessment. This form of assessment is in contrast to more conventional classroom measures and to numerous research-based normalized tests and surveys such as the Force Concept Inventory (FCI), the Force-Motion Concept Evaluation (FMCE) the Mechanics Baseline Test (MBT), and others [26-31].

All students enrolled in PNM have taken a first-level introductory physics course with a laboratory component. The curriculum for the second-level PNM course includes the following topic areas (which are quite typical in any second-level course): sound and waves, electricity and magnetism ( $\mathrm{E} \& \mathrm{M})$, light and color, optics, and (time permitting) introductory modern physics. The course consists of one 75-minute period each week where course content is delivered in an interactive lecture format. The second weekly period is 150 minutes in length. The double-length period is designed to give students a good deal of time to perform hands-on activities and experiments within a team-based environment. Because of the unique nature of the course, class size is limited to 16 students.

The non-traditional design and structure of the PNM course lends itself well to the development and use of alternative and perhaps more authentic assessment measures. Before discussing the assessment measures developed for use in the PNM course, a brief overview of the language of assessment will be shared. The intent of this overview is to provide a framework for assessment development and use at the individual course level and beyond.

\section{LANGUAGE COMmon to AsSESSMENT}

At the heart of assessment is student learning. Within the academy, whether at the course-, department-, program-, or institution-level, assessment is the name of the game. Institutions are responsible for providing assessment data, results, etc. to whatever accreditation agency or body is applicable. As faculty member, it is easy to sometimes think of assessment as "something we have to do for accreditation purposes." While this is certainly a true statement, assessment should be much more than that. If properly framed, assessment plan can serve a multitude of purposes.

The focus of any plan should be the assessment of student learning. As part of this plan we need to ask: Are our students learning what we intend for them to learn; and, what evidence do we have to document that this learning has actually taken (or is taking) place? While on the surface of things this might seem like a relatively easy question to answer. In practice, however, providing evidence of student learning takes careful thought and planning in order to create a blueprint that does more than just satisfy an institution's need for some data for their report to an accrediting body.

The language of assessment includes such terms as learning goals, learning objectives, and learning out- comes. Goals and objectives are very similar to one another. They essentially describe the intended scope and expected results of a teaching activity, course, or program. Goals express intended outcomes in general terms and objectives express them in specific terms [32]. A learning outcome refers to a statement that describes what the learner is to have achieved and can reasonably and reliably demonstrate by the end of a teaching activity, course, or program.

Measures to assess student learning typically fall into one of two categories: direct or indirect. A direct measure is one that "directly" evaluates student learning [33]. Direct measures include the use of actual student work and include items such as an

- exam or quiz,

- class assignment, project, report, etc.

- work-related task,

- interaction with a client (perhaps as part of an independent study or cooperative learning experience), or a

- musical or other performance.

It is not sufficient to simply use grades alone as a measure of student learning. Instead what is needed is a set of criteria used in the assessment, a clearly-framed analysis and discussion of results, and a feedback loop that can be linked to a specific department's program, general education, and/or the decision-making process at the institutional level. Simply reporting that X\% of the students got A's, $\mathrm{Y} \%$ got B's, etc. is not a sufficient direct measure of student learning.

An indirect measure of student learning is based on a report of perceived student learning [34]. Indirect measures can also provide information regarding how what a student has learned is valued by a specific stakeholder or set of stakeholders. For example, this information might come in the form of a report from a supervisor on an independent study project, a cooperative learning, or other work experience. Indirect measures provide additional information but are not as strong as direct measures in terms of truly capturing what a student has learned. In addition, indirect measures often involve an interpretation of an evaluation by a supervisor, or an assumption regarding just what the evaluation represents.

The next section provides a brief description of the PNM course format. Included within this description is a presentation of the learning outcomes for the course along with the associated direct measures used to assess the learning outcomes.

\section{THE PNM COURSE FORMAT}

Throughout a given semester, students in the PNM course have an opportunity to perform numerous hands-on activities designed to give them multiple opportunities to interactively engage with the course content. The topics explored within the PNM curriculum are fairly typical to any second-level introductory physics course and were briefly presented earlier.

The format for the PNM course stresses teamwork throughout all activities. Some activities are structured in a more traditional lab format, while many are structured in 


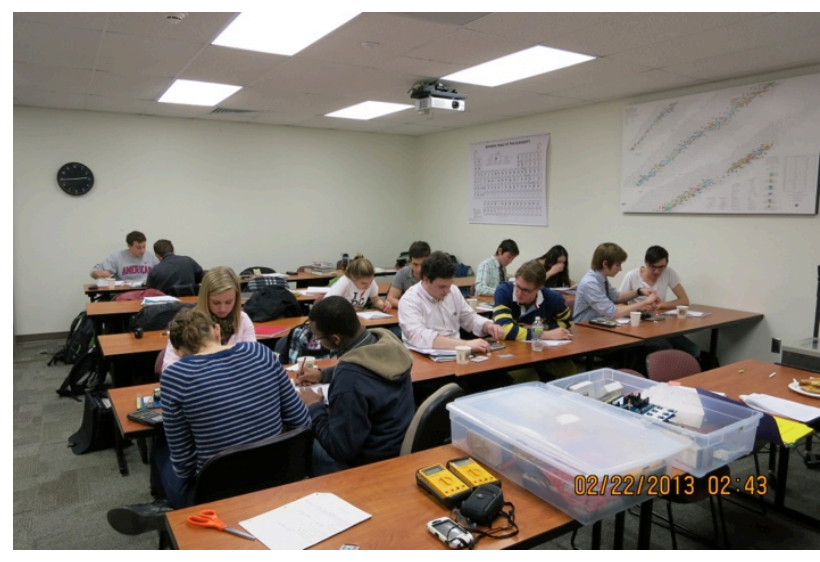

Figure 1. Teams of students working with electric circuits.

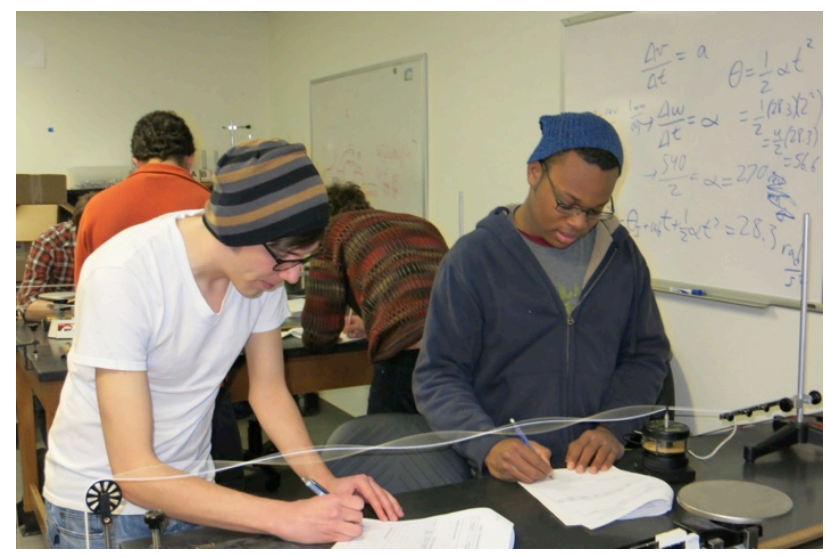

Figure 2. Student teams investigating standing waves on a string.

such away so as to provide students with an opportunity to pursue inquiry and investigation using a variety of techniques. Whether students are investigating sound waves in air, building a motor, or learning about light and color, a team approach takes center stage. Fig. 1 and 2 provide an illustration of how the classroom is structured based on a team environment.

Regardless of the activity, the class as a whole functions as a team. The team does not move on to a new activity until all class members have completed a particular activity. The end result is as individual teams of students finish an activity, they move into the role of teaching as- sistants, working to ensure that all of their classmates have fully completed a task or set of tasks. In this way, everyone's class time is utilized to the fullest extent possible. In addition, moving into the role of teaching assistant really aids students in solidifying their own understanding of the concepts central to each activity or set of activities. Instructor observation of the students at work in this type of team environment provides multiple data points for more authentic and holistic views of what the students are actually learning as the learning is taking place.

In terms of measuring what students are actually learning, the following subsection provides a look at the learning outcomes, objectives, and assessment measures used in the course. This information is shared with the students on the first day of class. In addition, frequent reminders of outcomes and objectives are made throughout the semester.

\section{A. Overview of Learning Outcomes and Assessment Measures}

On the course syllabus students are provided with details regarding the learning outcomes and associated assessment measures. The learning outcomes for the course are highlighted in Table I.

Learning outcomes $1-8$ are presented on the course syllabus in a very broad and generalized way. Table II builds on these learning outcomes by providing a specific set of learning objectives that are connected to each learning outcome. For clarity, the numbering scheme used in Table II corresponds to the numbering of the learning outcomes in Table I.

Table III highlights the assessment measures associated with the learning outcomes for the course. Again, this information is provided to the students through the course syllabus. Once again, the numbering scheme shown in Tables I and II is used.

Over and above the many opportunities to interactively engage with the course content through hands-on activities, the students also have a more unique opportunity to interact with the material. This opportunity comes in the form of preparing and presenting of a formal scientific research paper at a conference held on the last day of class. In the following section a presentation of the conference paper activity is shared along with its use as a direct measure of assessment.

TABLE I.

COURSE-SPECIFIC LEARNING OUTCOMES

\begin{tabular}{|l|}
\hline \multicolumn{1}{|c|}{ Learning Outcome } \\
\hline 1. Know basic physics terms. \\
\hline 2. Understand that units must be included when presenting or describing physical data and/or results. \\
\hline 3. Understand fundamental physical concepts and principles. \\
\hline 4. Understand appropriate problem solving techniques and methodologies. \\
\hline 5. Apply fundamental physical laws and principles. \\
\hline 6. Interpret and draw motion graphs. \\
\hline 7. Synthesize processes for obtaining a solution to a unique conceptual or numerical problem or situation. \\
\hline 8. Appreciate physics. \\
\hline
\end{tabular}


PAPER

The Student Conference: A Model of Authentic Assessment

TABLE II.

OBJECTIVES ASSOCIATED WITH LEARNING OUTCOMES

Objectives Specific to Learning Outcome

1.1 Writing a definition of a specified term.

1.2 Providing the term that best fits a particular context.

1.3 Selecting the best term when given a definition.

1.4 Distinguishing between scalar and vector quantities.

1.5 Identifying the appropriate usage of a specified term.

2.1 Converting from the SI to the British system of units and vice versa, using learned techniques.

2.2 Distinguishing between units of various physical quantities.

2.3 Recognizing the appropriate unit for a given term.

2.4 Expressing proper units with each numerical result or data obtained through direct measurement.

3.1Selecting the appropriate law or relationship given a physical description of a situation.

3.2 Writing a description of a particular law or principle.

3.3 Recognizing an appropriate concept or principle for a given task.

3.4 Citing examples which exemplify fundamental laws and principles.

3.5 Relating fundamental laws and principles to given physical situations in the classroom and laboratory.

3.6 Writing a professional paper on a topic which involves the role physics has played (or is playing) in terms of the development of some aspect of our highly technological society and that can be linked to a topic(s) covered in the course.

4.1Outlining problem solving methodologies.

4.2 Recognizing appropriate uses of problem solving techniques.

4.3 Recognizing improper uses of problem solving techniques.

4.4 Explaining one's choice of problem solving methodologies

4.5 Applying diverse modes of inquiry and critical reasoning to gather data and solve problems.

5.1 Distinguishing between appropriate and inappropriate applications of physical laws and principles.

5.2 Formulating solutions to problems based on appropriate laws and principles.

5.3 Solving problems that require the application of physical laws and principles.

5.4 Applying principles to new and different problem solving situations.

5.5 Demonstrating appropriate problem solving techniques.

6.1Drawing a graph of a particular motion of interest and determining its slope and y-intercept.

6.2 Describing the motion of an object in a given graphical representation.

6.3 Making interpretations based on a given graphical representation.

6.4 Selecting the graphical representation which best illustrates a given situation.

7.1 Using laws, principles, and concepts correctly and effectively.

7.2 Devising appropriate problem solving sequences leading to the solution of a unique problem.

7.3 Reorganizing given information into logical problem solving sequences.

7.4 Justifying the steps taken to solve a conceptual or quantitative problem.

7.5 Integrating various concepts learned into an effective problem solving strategy.

7.6 Demonstrating an understanding of the structures, patterns, principles, and values that affect the organization of societies and the relationship between the individual and society (with an emphasis on technology and its relationship to the individual and society).

7.7 Integrating problem solving and critical thinking skills using quantification, statistical analysis tools, and computer data manipulation.

8.1 Exploring real-world applications of the concepts, laws, and principles discussed.

8.2 Being encouraged to make connections between physics and one's individual major.

8.3 Making comparisons between various ways of looking at a given physical phenomenon.

8.4 Experiencing hands-on applications of physics, particularly through laboratory activities.

8.5 Exploring how scientists build models through which various physical phenomena can be analyzed and understood.

8.6 Analyzing how science works through the explicit examination of the historical development and current status of scientific methods, concepts, and principles.

8.7 Developing a respect for the finite resources of our planet, responsible use of technology and nuclear power, the limits of humane research, and the fragile wonders of the natural world. 


\section{Learning Experiences and Assessment Measures used in PNM}

1. You will have several opportunities to demonstrate your understanding of basic physics terms. These include:

- Regular homework assignments.

- Exams and quizzes that utilize a variety of question types (multiple choice, short answer, and numerical problem solving).

- Frequent collaborative hands-on activities (called Collabs) that will require you to demonstrate your understanding of basic physics terms.

- Preparation of professional conference paper.

2.Throughout ALL aspects of this course, whether in the classroom or during Collabs, the importance of units will be stressed.

3.You will have several opportunities to demonstrate your understanding of fundamental physics concepts and principles. These include:

- Regular homework assignments.

- Exams and quizzes that utilize a variety of question types (multiple choice, short answer, and numerical problem solving).

- Collabs.

- Preparation of professional conference paper.

4.Opportunities to demonstrate your understanding of appropriate problem solving techniques and methodologies include:

- Regular homework assignments.

- Exams and quizzes that utilize a variety of question types (multiple choice, short answer, and numerical problem solving).

- Collabs.

- Preparation of professional conference paper.

5.Opportunities to apply fundamental physical laws and principles include:

- Regular homework assignments.

- Exams and quizzes that utilize a variety of question types (multiple choice, short answer, and numerical problem solving)

- Collabs.

- Preparation of professional conference paper.

6.Some Collabs are designed to give you additional experience with graphical techniques. You may have opportunities to create graphs using our computer-based data acquisition system. In addition, you may also be required to produce and interpret some graphs that you have created by hand.

7.Opportunities to demonstrate your ability to synthesize processes used for both conceptual and numerical problem solving include:

- Regular homework assignments.

- Exams and quizzes that utilize a variety of question types (multiple choice, short answer, and numerical problem solving).

- Collabs.

- Preparation of professional conference paper.

8.Throughout the course you will have numerous opportunities to appreciate and value the physics you are learning. These opportunities include:

- Collabs.

- Preparation of professional conference paper.

- Qualitative and quantitative problem solving.

\section{Assessment OVERVIEW: The CONFEREnCE PAPER}

A written conference paper serves as a direct measure for assessing student learning in the PNM course. The conference paper activity provides students an opportunity to experience all aspects associated with writing and presenting a scientific research paper to an audience of their peers. Furthermore, over the course of a given semester, students are exposed to all aspects of preparing a professional paper for publication. The paper writing experience includes:

- the submission of an abstract,

- the preparation of a first draft for instructor review,

- the preparation of a second draft for formal peer review, and

- the preparation of a revised, camera-ready copy for publication in the conference proceedings.
Students then present their final papers at a class conference held at the end of the semester.

Requiring students to write a written research paper is not, in and of itself, unique. In most instances where a research paper is required, the only thing that is assessed is the end product. This type of assessment does not provide students with the necessary feedback they need to improve upon their work. While this type of assessment might provide some insight into student learning, it is certainly lacking in many respects. Assessment of the end product provides little or no information about the actual learning process. Moreover, this type of assessment does not shed much light on how student learning was enhanced as a result of the writing experience because of the significant lack of a vital feedback loop. It is one thing to have students write a research paper in a class; and, it is quite another to assess student learning throughout the entire writing experience. 
Within the PNM course assessment is done throughout all aspects of the writing process and is not based solely on the completed research paper. Each milestone of the paper-writing experience is designed to provide a "snapshot" to capture in real time what the students are actually learning as they are researching and writing their papers. To this end, a formal rubric is used as a record of student learning.

\section{A. The Conference Paper Assessment Rubric}

Unfortunately, instructors often give students a writing assignment for the sake of "giving them a writing assignment." In addition, the assessment of the students' writing is often subjective, and at best, superficial. While writing may be a useful tool to help students learn; using it as an assessment tool does pose some challenges. The use of a rubric can be an effective way to combat some of the challenges inherent in many writing assignments.

The rubric used to assess the formal PNM conference paper is illustrated in Fig. 3. The framework for the rubric centers on the major milestones of the paper writing process. A description of the significant assessment milestones of the paper writing process is provided in the following subsections.

\section{B. Abstract Submission}

At the very beginning of the semester, students are informed that they will have an opportunity to write a formal scientific research paper for publication in a class conference proceeding, and for presentation in a class conference to be held at the end of the semester. Specific details about the conference paper activity are provided to the students on the first day of class.

Students are allowed to choose a topic for their presentation that will permit them to demonstrate their understanding of a key topic area, or a set of topic areas, that will be discussed in class and were outlined in the previous section. Students are encouraged to choose a topic that might overlap with their major area of study, or something they are personally interested in and would like to know more about.

The students have approximately two weeks to select their topic and get instructor approval for it. In some cases, the instructor works with the students to help them narrow down and refine their topic choice. Once their topic has been approved, the students respond to a call for papers by submitting an abstract to the conference web site. From this point on, all aspects of the conference paper activity mirror those of an actual professional conference. The only difference is that no student papers are rejected at the abstract phase.

Approximately one week after the submission of abstracts, students are notified that their abstracts have been "accepted." Students are then "invited" to submit a first draft of their paper by a date set towards the midpoint of the semester. The submission of an abstract is the first milestone in the paper writing process. At this point, students begin the process of earning points towards their overall conference paper grade. Abstracts are not assessed for grammar and content at this point. Rather they are used as means for helping students put their research plans into clearer focus. In the next phase of the paper writing process, students carry out the necessary research and then prepare and submit a first draft of their papers for instructor review.

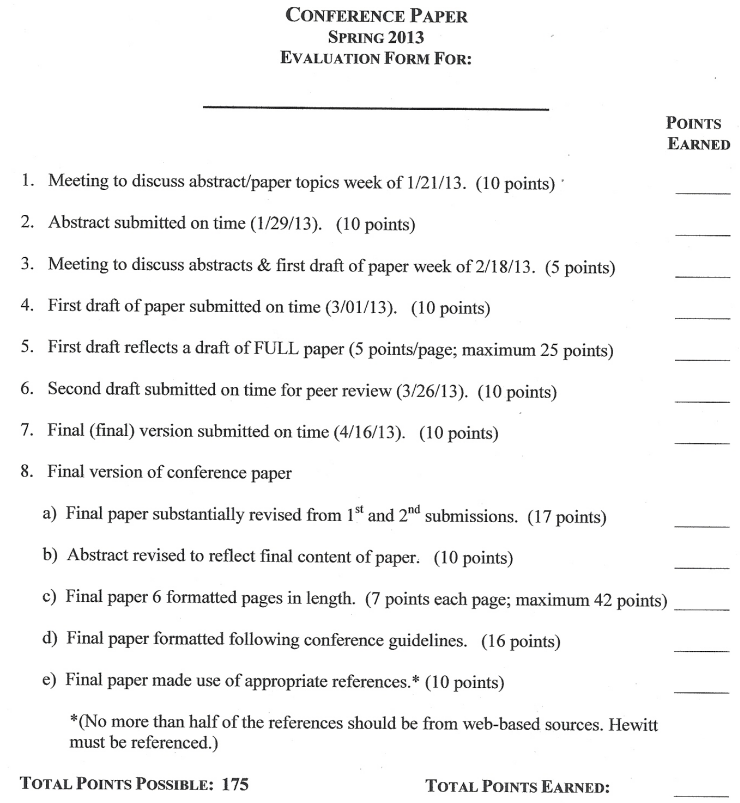

Figure 3. The conference paper assessment rubric.

\section{Preparation and Submission of First Draft for Instructor Review}

One requirement during this phase of the process is that students meet with the instructor individually to talk about the focus of their papers. Quite often students tend to try and cover too much material when they begin their research. The instructor works with them to help them narrow and focus their research into a manageable amount. During this discussion, considerable attention is given to the type and nature of the resource material that the students have gathered.

Once the abstract submission and acceptance phase is completed, students spend approximately $6-7$ weeks preparing the first draft of their full papers. Students must follow a formal set of guidelines as they prepare their first drafts, similar in nature to those used for the IGIP conference. The length requirement for the research papers is six formatted pages. This page length requirement is comparable to that of a standard $15-20$ page, 12 point font, and double-spaced research paper. For the first draft, students are required to submit five fully-formatted pages. The final paper must be a minimum of six fully-formatted pages.

The first drafts of the papers are reviewed solely by the instructor. The instructor provides each student with individual reviews of their paper and does so in a professional format. At this stage of the conference paper activity, the instructor's goal is two-fold. The first is to provide students with concrete feedback so that they might revise their papers and prepare a $2^{\text {nd }}$ draft; and the second is to serve as a model that students can refer to when they conduct their own individual peer reviews.

The feedback given to students focuses on both the quality as well as the content of the students' writing. Particular attention is paid to the specific physics content of the paper. Where discussion and descriptions might be sketchy, students are given suggestions and advice as to how they might enhance their writing through clarification and expansion of the physics content of their papers. Once students receive the instructor feedback, they receive a 
formal email from the instructor and are "invited" to submit a second draft of their full papers for peer review.

\section{Preparation and Submission of a Second Draft for Peer Review}

The next phase of the conference paper activity involves the preparation of a second draft that is submitted for peer review. Except for the fact that the papers are not blind reviewed, this phase of the activity mimics that of a professional peer review process. Students are given a set of guidelines for the peer review and are instructed to provide detailed comments on the paper that they've been assigned. Students spend approximately three weeks working on the second draft of their papers and are given one week to complete the peer review. Each student is assigned one paper to review.

In terms of assessment, the peer review activity is graded independently and is worth approximately $5 \%$ of the students' overall course grade. The independent assessment rubric used for the peer review is shown in Fig. 4. Once the peer review process has been completed students have about three weeks to complete and submit a final "camera ready" copy of their papers.

\section{E. Preparation of Final "Camera Ready" Copy}

Students are required to submit their camera ready copies approximately one week before the class conference which is held on the last day of class. One of the objectives of the conference paper activity is to provide students with a meaningful real-world experience. A second objective is to provide the instructor with a more authentic assessment measure that could be used in tandem with more traditional measures like exams and quizzes.

By moving through each milestone of the paper writing process, multiple opportunities present themselves for assessment of student learning. These opportunities were first noted in the assessment rubric for the conference paper (Fig.3). The rubric serves as an important marker for charting how the students' understanding of the subject matter covered within their papers has evolved over the course of the writing experience. The following sections provide an expanded view of the assessment process and showcases examples of actual student work.

\section{Authentic Assessment Using CONFERENCE PAPER WRITING EXPERIENCE}

Authentic assessment involves the use of activities and tasks that involve replicas of those which are faced by adults in the professional world [35]. Furthermore, authentic assessment involves providing activities, problems, or questions of importance that require students to use their knowledge to fashion presentations of their work both effectively, and creatively. The creation and use of rubrics to evaluate student performance is common within the domain of authentic assessment.

As outlined in the previous section, each phase of the paper writing process was assessed. Students were earning points towards their overall conference paper grade at each milestone of the activity. Overall, the conference paper activity constituted approximately $30 \%$ of the students' course grade.

At the beginning of the term, students are informed that throughout each phase of the project they will be "banking" points towards their overall conference paper grade.

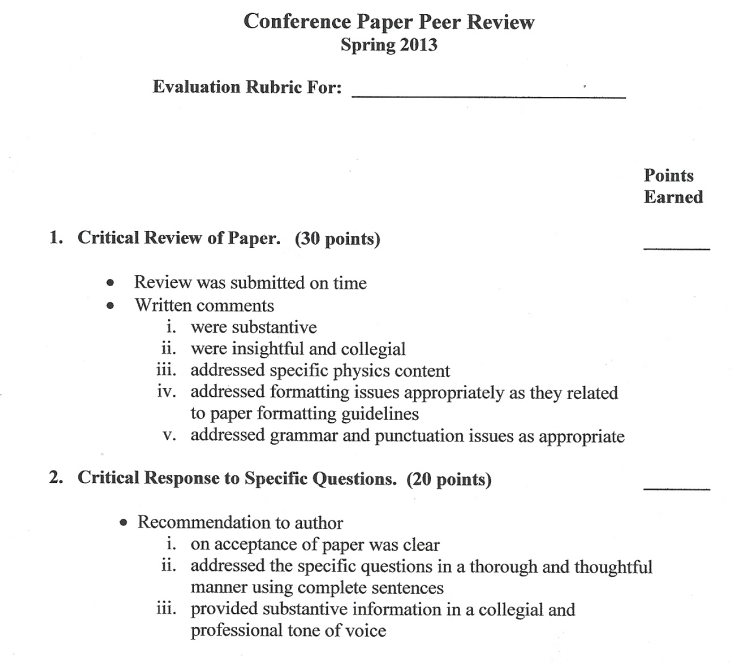

TOTAL POINTS POSSIBLE: 50

TOTAL POINTS EARNED:

Figure 4. Assessment rubric for the peer review.

Armed with this information, students are empowered as they complete each phase of the activity. Each phase of the activity also provides the instructor with a way to more clearly chart each student's overall learning in a deeper and more robust way. For example, during the peer review process, the instructor gains valuable information about student understanding based on the nature of the comments and feedback the students provide to their classmates. Traditional pencil and paper exams often do not provide as complete a picture of the true level and depth of a students' understanding about a topic or set of topics.

In the section that follows, some specific examples of how the assessment model described in the previous sections are utilized throughout the various phases of the conference paper activity. To provide a more authentic discussion, the actual course work of one student will be presented. This work exemplifies quality at all levels, and offers a realistic illustration of the assessment model utilized during the various phases of the conference paper activity.

\section{SPECIFIC EXAMPLES SHOWCASING THE ASSESSMENT PROCESS}

The subsections that follow provide a picture of the assessment model employed throughout the various milestones of the paper submission process. Specific illustrations will utilize the work of student Jamie Darken (with his permission) from the spring 2013 PNM class. Jamie's paper focused on the physics involved in the design of an acoustic guitar.

\section{A. Abstract Submission}

The first phase of the paper process required students to submit an abstract for instructor review. A website was set up for students to submit their abstracts and subsequent paper drafts. Upon submission of their abstract, each student was given a paper ID number that they used for later submissions. Fig. 5 shows the abstract that Jamie submitted along with the instructor's constructive feedback. 


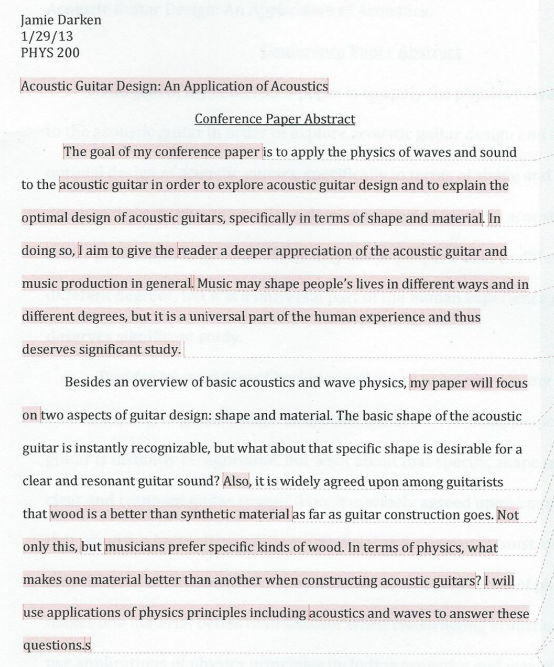

Figure 5. Abstract submission phase.

At the abstract phase students are just beginning to get started on their research and have just begun their library work. Further, the students are told that as they begin to formulate their research papers, the abstract should get modified and adjusted to better reflect the actual content of their papers. The instructor feedback is designed to help students focus on the physics content as well as to help them with things like professional language and structure.

\section{B. Submission of First Draft for Instructor Review}

Following the submission of their abstracts, students have approximately one month to prepare the first drafts of their papers. Students were given a formal set of professional paper formatting guidelines that they were to follow as they prepared their drafts. The first drafts of the papers are reviewed by the instructor. Each student receives a detailed and comprehensive set of constructive comments from the instructor. Again, the focus is on the specific physics content along with the overall formatting of the paper. Fig. 6 shows a sample of the first page of Jamie's first draft.

While the instructor review process does take a good deal of time, it is time well spent. The estimated amount of time given to each paper at this phase of the process is approximately $2-3$ hours. Because the class size is limited to 16 students, this is manageable. For larger class sizes, one could make use of TAs to assist with the reviews. Important to note is the fact that this is the only point in the writing process where the instructor provides this type of substantive feedback. It is the experience of the author that once students receive this feedback, they really understand the level of quality expected for the paper. In addition, students quickly learn the importance of using the language of physics in a deep and meaningful way as they present the research they've done on their respective topics.

\section{Submission of Second Draft for Peer Review}

Upon receipt of the instructor's feedback on their first drafts, students have approximately 3 weeks to complete a second draft of their paper. Students are then assigned

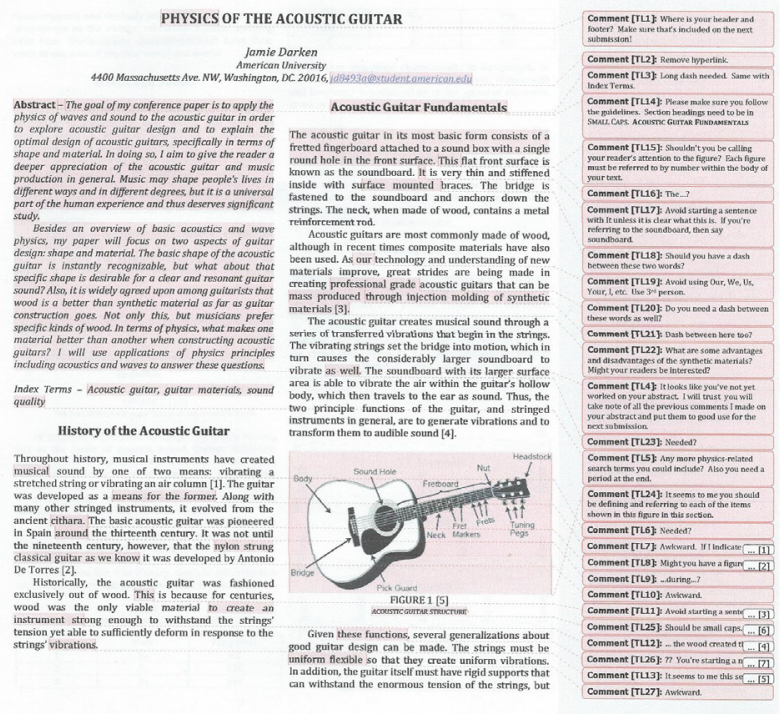

Figure 6. First draft submission and instructor's feedback.

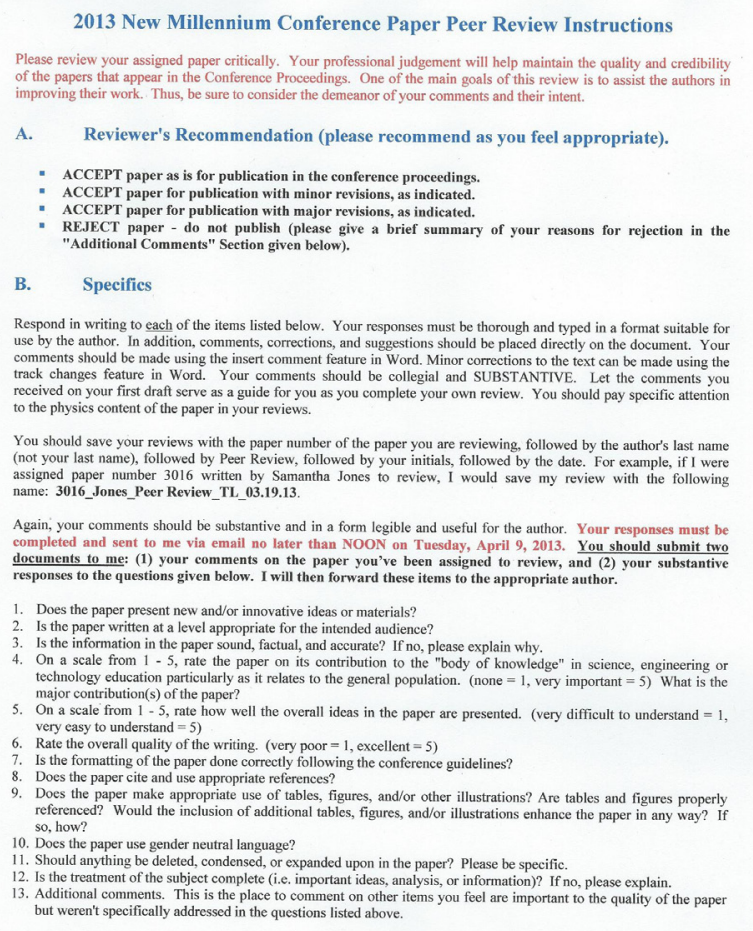

Figure 7. The peer review guidelines.

one paper that they will review as part of the peer review phase of the paper writing process. To that end students are given a set of peer review guidelines. These guidelines are illustrated in Fig. 7.

Using the instructor feedback they received on their first drafts as a model, students were instructed to provide substantive written feedback on the paper they were assigned to review using the "track changes" and "comment" features available in Microsoft Word. In addition, students were also required to provide a detailed response to a set of questions that were part of the peer review guidelines.

Fig. 8 provides an illustration of the review that Jamie conducted on classmate Juan Heilbron's paper (presented with his permission). Juan's paper was on the physics of 
electric guitars, so the pairing of these students for the peer review was done intentionally. Given that Jamie and Juan were writing on similar topics, the quality of the feedback they could provide one another was enhanced. In most instances, students were assigned papers for peer review that in some way overlapped with the topic of their own research.

While a number of comments on the page represented in Fig. 8 are stylistic in nature, the overall quality of the physics-specific comments throughout the entire paper was excellent. For example, specific comments Jamie provided Juan regarding the physics content of his paper include the following:

- "The pickups don't register the sound specifically. They register the vibrations of the strings. It's a subtle but key difference."

- "You mean they are permanent magnets or that their magnetic domains are easily aligned?"

- "You're leaving out a crucial part of Faraday's Law: the wire."

- "I think your discussion of physics can be enhanced here. How exactly do all the variables related and what does each one do to the frequency?"

- "Tension is still a factor, it's just constant across the strings."

Comments such as these assist the instructor in assessing the level of physics understanding of the student conducting the review. This type of assessment is often much more revealing than any kind of traditional assessment measure could provide. In addition, sometimes the students' comments pertain to material the students learned in their first-level physics. Comments of this type provide an added bonus in that the instructor has the opportunity to see how students are making connections between the first- and second-level physics courses. The bonus for the student comes in discovering how connected the material covered in the two courses really is.

The peer review assessment rubric originally shown in Fig. 4 is provided to the students as they begin their peer reviews. Once the peer reviews have been completed, the students receive a copy of the rubric along with their scores for each of its components.

\section{Submission of Final "Camera-Ready" Copies}

Fig. 9 is an illustration of Jamie's final paper submission. Through the final paper Jamie demonstrated keen attention to formatting details. In addition, his discussion of the physics content of his paper was strong and appropriate for an audience of his peers.

Near the beginning of the paper writing process, students were shown the conference paper assessment rubric (Fig. 3). Hence, they were advised in advance as to how their work would be assessed. The students knew understood that they were "banking" points towards their overall paper grade through each part of the process. Students earned points towards their overall paper grade as they completed each required part of the paper. The final copy of their papers were worth a substantive amount of points as it is here that they are demonstrating that they've utilized the feedback they'd been given. In addition, each phase of the process was designed to empower students to make their final papers the best that they could be.

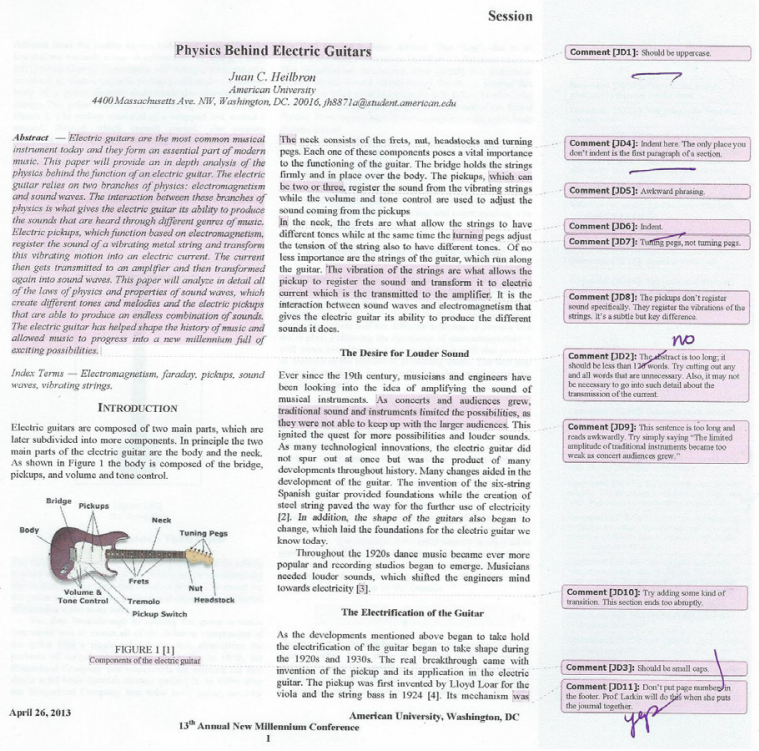

Figure 8. Sample student peer review.

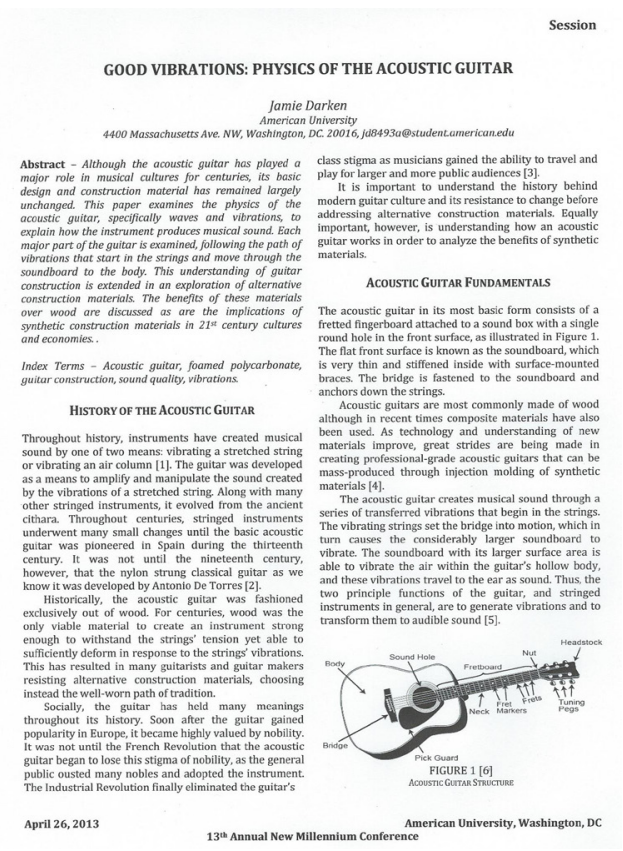

Figure 9. Final camera-ready submission.

\section{E. The Class Conference}

On the last day of class a formal conference was held so that students could present their papers. All student papers were published in a bound conference proceedings and distributed on the day of the conference. Two days prior to the actual conference, students met with the instructor in order to practice their formal presentations. Students were required to prepare a PowerPoint for use during their presentations. These practice sessions provided the instructor with an additional opportunity to provide students with constructive feedback. In addition, these sessions provided another data point for issuing a grade for the conference presentation.

During the conference, students conducted a formal peer review of the presentations made by their peers. A copy of the rubric used by the students for these reviews is shown in Fig. 10. 


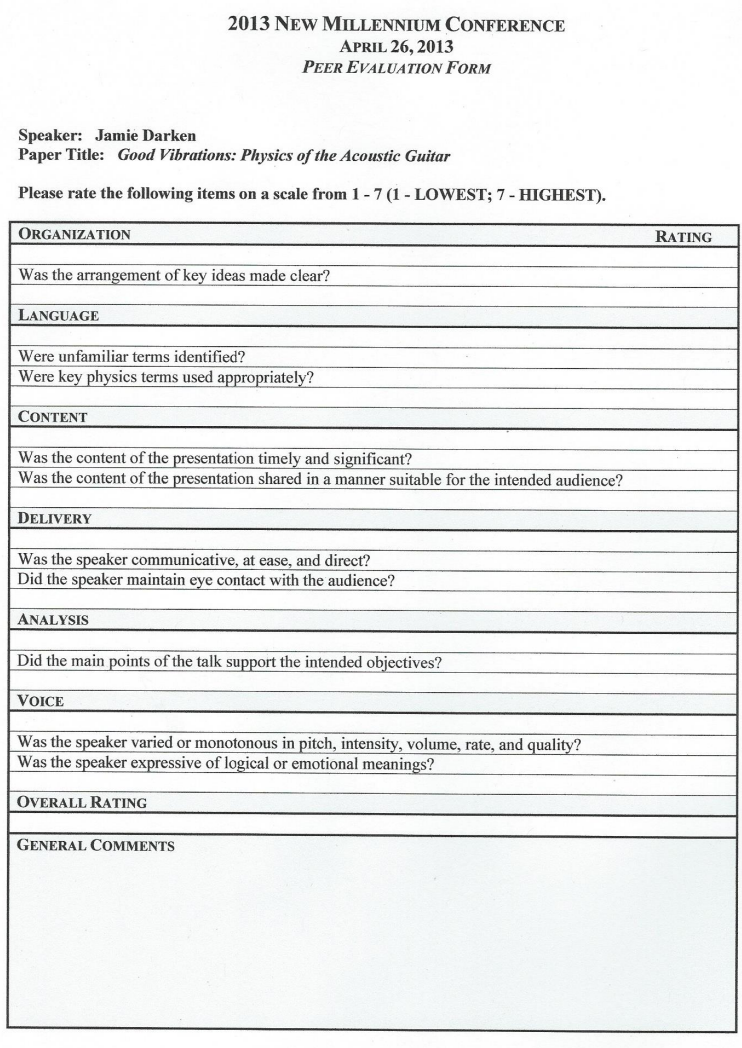

Figure 10. The presentation peer review rubric.

Immediately after the conference, students were given the feedback provided them by each of their peers. The instructor never looked at this feedback nor did it in any way affect their conference presentation grade. The intent of the feedback was merely to provide constructive comments to each student author as a means for reflection and self-improvement.

The entire conference was also video-taped. There were many student and faculty guests at the conference. In addition, some parents were in the audience. A few days after the conference, students were given copies of the conference DVD. Students could then view the conference and their individual presentations at their leisure, again for the purposes of reflection and self-improvement.

\section{SUMMARY}

One of the goals of having students write a scientific research paper and then present it at a class conference was to give them an opportunity to conduct research on topics that they deemed interesting; while simultaneously allowing them to uncover, on their own, links between physics and their major or other interest area. Oftentimes students taking a traditional physics course have difficulty relating the topics studied to real-world situations and applications. The research paper experience can perhaps give a more authentic voice to the physics the students are learning about in the classroom.

An additional goal of the paper writing activity was to provide students with a genuine experience in which they could demonstrate to the instructor that they had a solid understanding of the physics content covered during the term. The conference paper activity clearly provided the instructor with more meaningful and robust information about student learning. Because each milestone of the activity had an assessment component, the instructor was often able to help students to correct a flaw in their thinking while the learning was actually taking place. More traditional assessment measures like exams and quizzes are typically given "post mortem" and therefore do not have a built-in mechanism to correct flawed thinking like authentic, formative measures do. The conference paper activity provided students an opportunity to demonstrate, at a deeper level, their understanding of physics while simultaneously providing them with a learning experience that would serve them well, long after the semester comes to an end.

Having students write a formal research paper and then present it during a formal class conference also provided the opportunity for improvement of both written and oral communication skills. Having strong communication skills is of critical importance as students begin to prepare their resumes and start applying for internships, summer co-op experiences, or for professional positions after graduation. College faculty are routinely asked to prepare letters of recommendation for students that they've had in class. Without exception, every recommendation comes with instructions to comment on students' written and oral communication skills. Having had students go through the conference paper activity described here provides them with an invaluable resource. Students frequently cite the PNM conference on their resumes and provide a copy of their paper to future employers as evidence of their writing skills. In fact, a student who took the spring 2013 PNM course recently expressed that while submitting applications for professional employment after graduation, he's been using his conference paper for several of his job applications and it has garnered a great deal of attention [Andrew Stern, personal communication, Nov. 20, 2013]!

From both the instructor and student perspective the conference paper activity is a "win-win." The instructor gets a chance to add an alternative and more authentic assessment tool to the course design; and, the students have a chance to produce a scientific research paper that has the potential to do much more than simply help them learn physics.

\section{ACKNOWLEDGMENT}

The author wishes to acknowledge all of the students in her past PNM classes. A special thank you goes to the students in the spring 2013 class. You were an amazing group of students to work with! She'd also like to thank her outstanding TAs (Kaitlyn Martell, Ben Chesneau, and Alex Marshall) who provided invaluable assistance during the second round of paper reviews. A special thank you also goes to Jamie Darken and Juan Heilbron for granting me permission to cite examples from their original class work.

\section{REFERENCES}

[1] Jones, T. H. and Paolucci, R. (1998). The learning effectiveness of educational technology: A call for further research. Educational Technology Review, (9), 10 - 14.

[2] Deslauriers, L., Schelew, E., and Wieman, C. (2011). Improved learning in a large-enrollment physics class. Science, 332, $862-$ 864. http://dx.doi.org/10.1126/science. 1201783

[3] Smith, M. K., Wood, W. B., Adams, W. K., Wieman, C., Knight, J. K., Guild, N., and Su, T. T. (2009). Why peer discussion improves student performance on in-class concept questions. Science, 323, 122 - 124. http://dx.doi.org/10.1126/science.1165919 
[4] Mazur, E. (1997). Peer instruction: A user's manual. Upper Saddle River, N.J.: Prentice Hall.

[5] Hammer, D. (1989). Two approaches to learning physics. The Physics Teacher, 27(9), 664 - 670. http://dx.doi.org/10.1119/ 1.2342910

[6] Van Heuvelen, A. (1991). Learning to think like a physicist: A review of research-based instructional strategies. American Journal of Physics, 59(10), 898 - 907. http://dx.doi.org/10.1119/ $\underline{1.16668}$

[7] Hestenes, D., Wells, M., and Swackhamer, G. (1992). Force concept inventory. The Physics Teacher, 30(3), 141 - 153. http://dx.doi.org/10.1119/1.2343497

[8] Maloney, D. (1994). Research on problem solving: Physics. In D. L. Gabel (Ed.), Handbook of Research on Science Teaching and Learning (pp. 327 - 354). New York: Macmillan Publishing Company.

[9] Reif, F. and Scott, L. A. (1999). Teaching scientific thinking skills: Students and computers coaching each other. American Journal of Physics, 67(9), 819 - 831. http://dx.doi.org/10.1119/ 1.19130

[10] Arons, A. B. (1990). A guide to introductory physics teaching. New York: John Wiley \& Sons.

[11] Halloun, I. A. and Hestenes, D. (1985). The initial knowledge state of college students. American Journal of Physics, $\underline{53}(11)$, 1043 - 1055. http://dx.doi.org/10.1119/1.14030

[12] McCloskey, M., Caramazza, A., and Green, B. (1980). Curvilinear motion in the absence of external forces: Naïve beliefs about the motion of objects. Science, 210, 1139 - 1141. http://dx.doi.org/10.1126/science.210.4474.1139

[13] McDermott, L. C. (1984). Research on conceptual understanding in mechanics. Physics Today, 37, $24-32$. http://dx.doi.org/ $\underline{10.1063 / 1.2916318}$

[14] McDermott, L. C. (1991). A view from physics. In M. Gardner, J. Greeno, F. Reif, A. H. Schoenfeld, A. diSessa, and E. Stage (Eds.), Toward a scientific practice of science education (pp. 3 30). Hillsdale, NJ: Lawrence Erlbaum Associates.

[15] Hammer, D. (1996). More than misconceptions: Multiple perspectives on student knowledge and reasoning, and an appropriate role for educational research. American Journal of Physics, 64, 1316 1325. http://dx.doi.org/10.1119/1.18376

[16] Reif, F. (1995). Millikan lecture 1994: Understanding and teaching important scientific thought processes. American Journal of Physics, 63(1), 17 - 32. http://dx.doi.org/10.1119/1.17764

[17] Astin, A. W. (1993). Assessment for excellence: The philosophy and practice of assessment and evaluation in higher education. Phoenix, AZ: American Council on Education and the Oryx Press

[18] Laws, P. W. (1991). Calculus-based physics without lectures. Physics Today, 44(12), 24 - 31. http://dx.doi.org/10.1063/ $\underline{1.881276}$

[19] Beichner, R. J., Saul, J. M., Allain, R. J., Deardorff, D. L., and Abbott, D. S. (2000). Introduction to SCALE-UP: StudentCentered Activities for Large Enrollment University Physics. Proceedings of the Annual Meeting of the American Society for Engineering Education, Seattle, Washington, Session 2380.

[20] Hake, R. R. (1998). Active-engagement vs. traditional methods: A six thousand student study of mechanics test data for introductory physics courses. American Journal of Physics, $\underline{66}(1), 64-74$. http://dx.doi.org/10.1119/1.18809

[21] Cummings, K., Marx, J., Thornton, R., and Kuhl, D. (1999). Evaluating innovation in studio physics. Physics Education Research: A Supplement to the American Journal of Physics, 67(7), S38 S44.
[22] Thornton, R. and Sokoloff, D. (1990). Learning motion concepts using real time microcomputer-based laboratory tools. American Journal of Physics, $\underline{58(9), 858-867 . ~ h t t p: / / d x . d o i . o r g / 10.1119 / ~}$ $\underline{1.16350}$

[23] Redish, E. F. and Steinberg, R. N. (1999). Teaching physics: Figuring out what works. Physics Today, 52(1), $24-30$. http://dx.doi.org/10.1063/1.882568

[24] Van Heuvelen, A. (1991). Overview, case study physics. American Journal of Physics, $\underline{59(10),} 898-906$. http://dx.doi.org/10.1119/1.16668

[25] Teresa L. Larkin (2013, January). The Evolution of Assessment within an Introductory Physics Course. International Journal of Engineering Pedagogy (iJEP), Vol. 3, Special Issue , 1, pp. 39 48. Kassel University Press GmbH, Kassel, Germany. eISSN: 2192-4880. http://dx.doi.org/10.3991/ijep. v3iS1.2393.

[26] Larkin-Hein, T. (2001). Writing as a teaching and learning tool in SMET education. Journal of SMET Education: Innovations and Research, 2(2/3), $25-35$.

[27] Larkin, T. L. (2009). Give it a 'TWIST!' Turning writing into student thinking. IEEE/ASEE Frontiers in Education Conference, Austin, Texas. Electronic proceedings, Session T4C, pp. $1-4$. IEEE Catalog Number: CFP09FIE. ISBN: 978-1-4244-4715. Library of Congress: 79-640910. ISSN: 0190-5848.

[28] Larkin, T. L., (2007). Writing: A global Active learning tool in STEM education. International Conference on Engineering and Computer Education (ICECE 2007), Santos/Monguaguá, Brazil, Plenary Session II.

[29] Kalman, C. S. (2007). Successful science and engineering teaching in colleges and universities. Bolton, MA: Anker Publishing Company, Inc.

[30] Larkin, T. L. (2011, March). The inclusive classroom: A researchbased approach to enhance learning. Invited paper at the 40th IGIP International Symposium on Engineering Education, São Vicente at the Metropolitan region of Baixada Santista, Brazil.

[31] Larkin, T. L. \& Budny, D. (2008). Peer review from a student perspective. IEEE/ASEE Frontiers in Education Conference, Saratoga Springs, New York. Electronic proceedings, Session F2C, pp. 14 - 15. IEEE Catalog Number: CFP08FIE-CDR. ISBN: 978-14244-1970-8. Library of Congress: 79-640910. ISSN: 0190-5848.

[32] www.assessment.uconn.edu/HowToWriteObjectivesOutcomes.pdf . (Accessed 10.24.12).

[33] Walvoord, B. E. (2004). Assessment clear and simple: A practical guide for institutions, departments and general education. San Francisco, CA: Jossey-Bass (A Wiley imprint).

[34] http://www.anokaramsey.edu/en/about/Information/Assessment/M easures.aspx. (Accessed 12.30.12).

[35] Wiggins, G. P. (1993). Assessing student performance. San Francisco: Jossey-Bass Publishers.

\section{AUTHOR}

T. L. Larkin is an Associate Professor of Physics Education with the Physics Department at American University, Washington, DC 20016-8058 USA (email: tlarkin@american.edu).

This article is an extended and modified version of a paper presented at the ICL2013 Special Session "Talking about Teaching 2013" (TaT'13), held from 25 to 27 September 2013 at Kazan National Research Technological University, in Kazan, Russia. Submitted 30 November 2013. Published as re-submitted by the author 17 March 2014. 